\title{
Recreation of esthetic smile from flared anterior teeth with midline diastema utilizing zirconia ceramic fixed bridge: A case report
}

\author{
Souvik Bakshi ${ }^{1}$, Rajeev Gupta ${ }^{2}$, Komal $^{3 *}$, Sumit Verma ${ }^{4}$, Ijaz Ahmad Bhat ${ }^{5}$ \\ ${ }^{1,3-5}$ Post Graduate, ${ }^{2}$ Professor, ${ }^{1-5}$ Dept. of Prosthodontics Crown \& Bridge, Himachal Dental College, Sundar Nagar, Mandi, \\ Himachal Pradesh, India
}

*Corresponding Author: Komal

Email: komalathania88@gmail.com

\begin{abstract}
Proclination of maxillary incisors is considered as the main manifestations of pathological migration. Diastema is defined as no proximal contacts between adjacent teeth. Dentofacial discrepancies negatively affect the speech, masticatory function and aesthetics. Where orthodontic and surgical treatments can not be applied, it is inevitable to carry out the restorative treatments to accomplish the function and the aesthetics. With adequate diagnosis and treatment planning, it is possible to recreate a healthy and well functioning dentition with good occlusion, sufficient masticatory function, and improved esthetics that will enhance the psychological status of the patient after correcting the elongation and the migration of the anterior teeth.
\end{abstract}

Keywords: Aesthetics, Fixed Partial Denture, Monolothic zirconia, Midline Diastema, Pathological migration.

\section{Introduction}

The Smile is the most prominent feature of face and teeth are the most important elements of the smile. The presence of an anterior midline diastema and increased overjet in particular has a negative effect on detofacial harmony. ${ }^{1}$ Unwanted migration of maxillary anterior teeth is referred to as "spreading", "splaying" "fanning", "tipping" or "flaring". 2 Midline diastema is spaces of varying magnitude between the crowns of fully erupted maxillary and mandibular central incisors. The presence of diastema in the anterior aesthetic zone can be displeasing to a person's smile and many patients are motivated to improve their appearance either with orthodontic treatment or restoratively with veneers, crowns, and/or composite resin bonding. ${ }^{3}$ Pathological tooth migration may include extrusion and rotation of anterior teeth. The ability to withstand tooth forces is led by a healthy periodontium, bone density, occlusal stability, occlusal arch integrity integrity, and the absence of irregular external forces (such as parafunctional habits) that causes orthodontic motion. ${ }^{2}$ In these cases, conventionally orthodontic treatment will correct the anterior increased overjet and provide the closure of the diastema. But in some situations, orthodontic treatment is not possible either due to increased age or patient desire for immediate results, so in these cases prosthodontic rehabilitation appear as treatment of choice to achieve desired results. For this purpose the composites, porcelain laminate veneers, metal-ceramic restorations, all-ceramic crowns and zirconia restorations can be used. ${ }^{4,5}$ Newly core material for allceramic Fixed Prosthesis like yttrium-oxide partiallystabilized (Y-TZP) zirconia. Y-TZP shows superior strength, better mechanical performance, high fracture resistance, more abrasion resistance, color stability and aesthetics than other all-ceramic cores. Additionally, Oxide ceramic exhibits high biocompatibility with low bacterial surface adhesion, reduced thermal conductivity. ${ }^{6}$ This clinical report presents a case with labial migration of maxillary incisors with increased midline diastema which was managed with prosthodontic rehabilitation.

\section{Case Report}

\section{Diagnosis and treatment planning}

A 50 years old female patient was referred to us with a chief complaint of spacing in upper front teeth (Fig. $1,2)$. Her history revealed that she had space in between her upper front teeth $[11,21]$ since 5 years and 
space was enlarging slowly since then and she wanted to close the space and improve her appearance.

On clinical examination, space of more than 10 $\mathrm{mm}$ were found with associated teeth and overjet of $3 \mathrm{~mm}$ was seen with normal overbite and class 1 malocclusion. Radiographic examination showed moderate, horizontal bone loss in maxillary anterior region. Based on the clinical \& radiographic presentation, we believed that the traumatic bite and high frenal attachment was the main reason for the occurrence of pathological tooth migration and midline diastema. Orthodontic treatment was suggested but since she wanted an Immediate treatment The treatment plan for maxillary anterior teeth was decided as initial periodontal therapy, endodontic therapy, followed by prosthodontic rehabilitation. Considering the good prognosis of present anterior teeth, and mininmal gingival recession and patient desire to improve aesthetics immediately, treatment was planned to use $12,11,21$ as abutment teeth, followed by the construction of an extra central incisor to cover midline diastema and converting 21 into lateral incisor inturn giving four unit monolithic Zirconia fixed partial denture bridge from 12 to 21 to cover the space in midline and attain better aesthetics and pleasant smile.

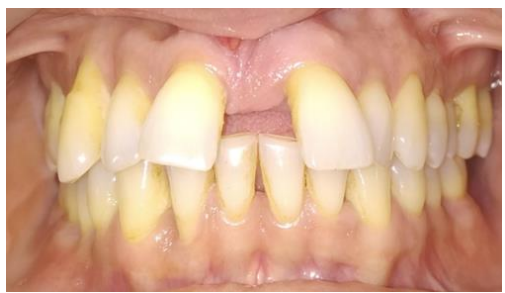

Fig. 1: Preoperative photograph showing midline diastema more than $10 \mathrm{~mm}$

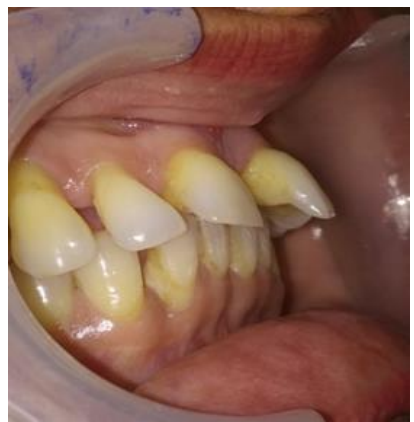

Fig. 2: Lateral profile of patient showing increased overjet

\section{Clinical procedure}

Periodontal therapy including scaling, root planing, and subgingival curettage were completed.and Root canal treatment for teeth 11,21 was completed

First appointment: After the initial endodontic and peridontal therapy, Alginate impressions of maxillary and mandibular dentition were made according to the conventional technique and poured in dental stone to make diagnostic casts [Fig. 3]

The mock up grinding of teeth $(11,12,21)$ were done on the diagnostic cast to replicate final tooth preparation and mock wax up was done to simulate final fixed prosthesis. [Fig. 4]

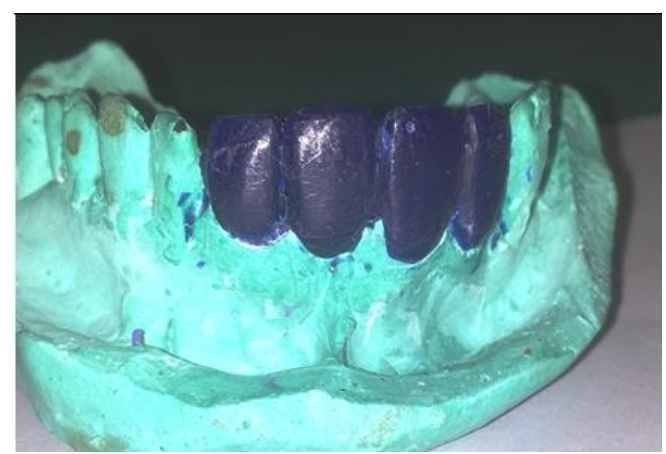

Fig. 3: Mock up wax pattern on diagnostic cast

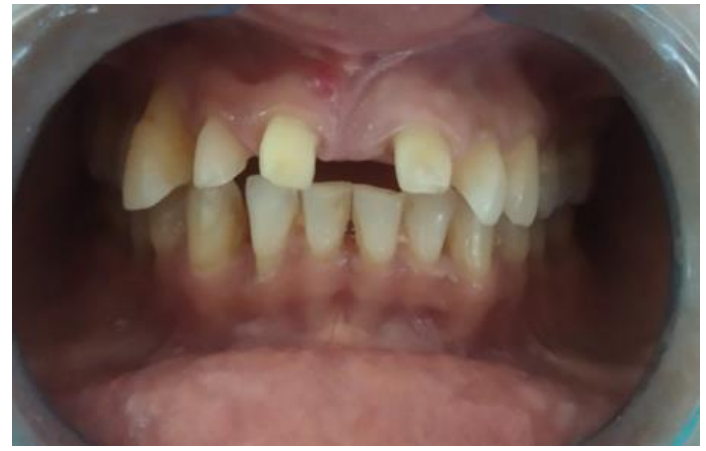

Fig. 4: Final tooth preparation with respect to $11,12,21$

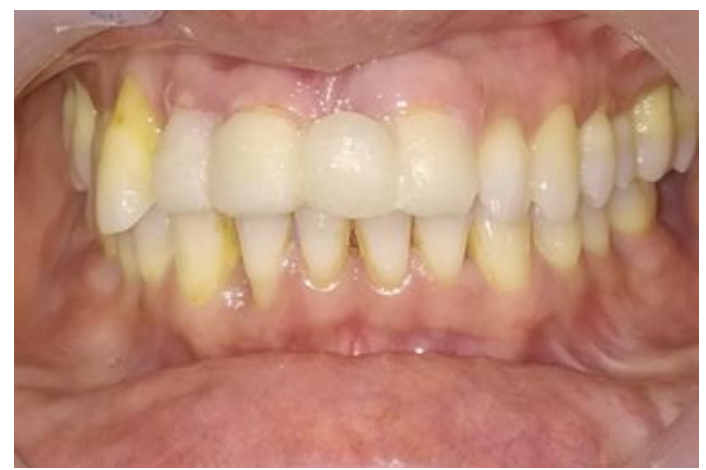

Fig. 5: Temporary crowns in place 
Second Appointment: full coverage crown preparations with equigingival finish line configuration were completed on 11, 12, 21 for Zirconia restorations were done. Since the tooth was endodontically treated, more reduction was made on the labial side of the teeth to allow the crown to be fabricated in a good teeth alignment and required lingual reduction was done to relieve traumatic occlusion. The tooth was prepared according to mock up on diagnostic cast (Fig. 4,5). Impresion was made using elastomeric impression followed by Shade matching. Bite record was and Temporary crown were cemented.

Final appointment: Temporary crowns were removed. final prosthesis was tried in and checked for high point and adaptation, and final prosthesis was cemented with permanent cement. (Fig. 6,7).
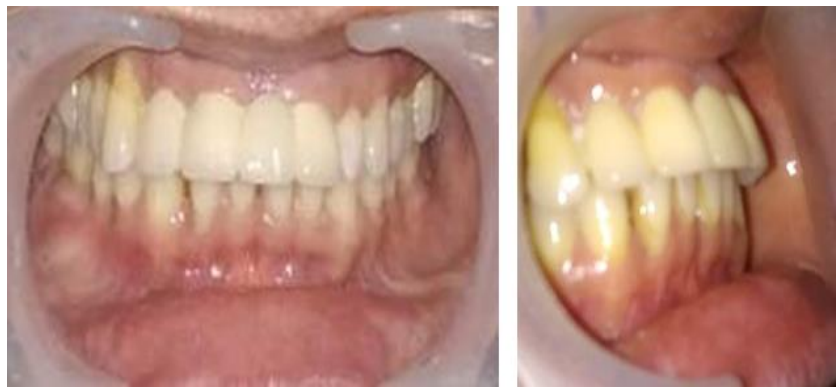

Fig. 6: Post operative photograph with final four unit Zirconia prosthesis in place

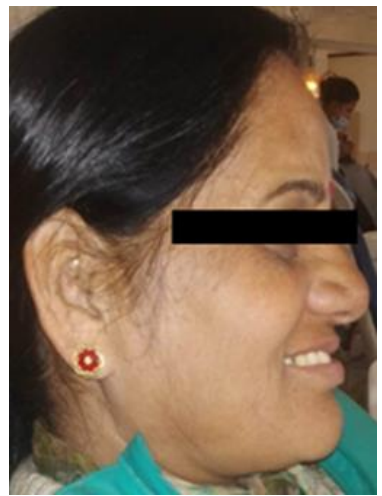

Fig. 7: Postoperative Lateral profile of patient

\section{Discussion}

The goal of an esthetic makeover is to develop a peaceful and stable masticatory system, where the teeth, tissues, muscles, skeletal structures and joints all function in harmony (Peter Dawson). ${ }^{7}$ Periodontal bone loss is one of the major factors responsible for pathological tooth migration. However, many authors have believed that the etiology is multifactorial. Pathological tooth migration was also reported as having association with factors like traumatic occlusion, soft tissues pressure, gingival growth, periodontal tissue inflammation, and oral habits. ${ }^{8}$ In the present case, the maxillary incisors had protruded facially and incisally, Based on the clinical \& radiographic presentation, we believed that the traumatic bite and high frenal attachment was the main reason for the occurrence of pathological tooth migration. More than one of these factors may be present in an individual patient. Several methods have been documented for treating maxillary midline diastema with the assistance of different dental disciplines including orthodontics, prosthodontics, operative dentistry, and periodontology. ${ }^{4,9}$ Orthodontic correction represents a conservative technique to achieve a pleasant esthetic result but is expensive and time consuming. Furthermore, orthodontic treatment alone may not be adequate to establish ideal proximal contacts with sufficient vertical and horizontal overlaps when tooth size and shape discrepancies exist. $^{4,9}$ Restoration of maxillary midline diastema with direct bonding, laminate veneers, or crowns each provide the opportunity to control both tooth size and form. ${ }^{4}$ An orthodontic treatment option is often refused by adult patients due to the long treatment time and the desire for immediate esthetic results. A variety of prosthetic approaches can be applied in cases of diastema. ${ }^{10}$ For example, laminate veneer restorations, metal-supported restorations, all-ceramic restorations and zirconia ceramic restorations. Zirconia-based Fpds have been considered the restorations of choice with acceptable long-term survival rates and esthetic qualities. $^{11}$ In present case, because of aesthetic excellence and high stress resistance, zirconia framework ceramic fixed posthesis was used and the pathologically migrated maxillary anterior teeth were realigned prosthodontically back into a more upright position. Tooth preparation led to correction of alignment of maxillary anterior teeth, so the incisal edges moved lingually, and traumatic occlusion was relieved by proper lingual reduction and the lower lip 
slides in front of the maxillary teeth for a more normal lip seal during swallowing.

\section{Conclusions}

This clinical report presents a relatively simple and rapid way of managing flared maxillary anterior teeth with diastema by prosthodontic rehabilitation. As a result, in our case report, the patient's aesthetics, phonation, and function were restored by the appropriate planning and choice of zirconia fixed prosthesis technique.

\section{Source of Funding}

None.

\section{Conflict of Interest}

None.

\section{References}

1. Guven, Sedat \& Karaman, Tahir \& Ünal, Mehmet \& Melek, I.C. Rehabilitation of open bite with diastema using zirconia ceramic crowns: Case report. J Int Dent Med Res 2013;6:88-91

2. Greenstein G, Cavallaro J. and Scharf D, Tarnow D. Differential diagnosis and management of flared maxillary anterior teeth. JADA 2008;139:715-23.

3. Kinchanakodi A.M, Shetty M.B, Parveen K, Shamshad \& Suhaim. Resin Retained Bridge a Treatment Modality for Diastema Closure: A Case Report. Int J Collaborative Res Int Med Public Health 2016;8:9.
4. Nazmiye $S$, Sabire Is Multidisciplinary Management of a Severe Maxillary Midline Diastema: A Clinical Report Journal of Prosthodontics 2018:1-5 C;2018 by the American College of Prosthodontists

5. Yoshio Furuse A, Jacomino Franco E, Mondelli J. Esthetic and Functional Restoration For An Anterior Open Occlusal Relationship With Multiple Diastemata: A Multidisciplinary Approach. J Prosthet Dent 99(2):91-5.

6. McLean JW. Perspectives on dental ceramics. In: Dental Ceramics. Proceedings of the First International Symposium on Dental Ceramics. Chicago: Quintessence 1984:13-40

7. Bhuvaneswaran M .Principles of smile design. J Conserv Dent. 2010;13(4):225-32.

8. Bajaj P., Madan N, Gupta N. Aesthetic and functional management of flared maxillary anterior teeth. J Innov Dent 2011;1(2).

9. Furuse AY, Franco EJ, Mondelli J: Esthetic and functional restoration for an anterior open occlusal relationship with multiple diastemata: a multidisciplinary approach. $J$ Prosthet Dent 2008;99:91-4

10. Chu C.H, Zhang C.F, \& Jin L.J. Treating a maxillary midline diastema in adult patients: a general dentist's perspective. J Am Dent Assoc 2011;142;(11):1258-64 .

11. Kassardjian V, Varma S, Andiappan M, A systematic review and meta-analysis of the longevity of anterior and posterior all ceramic crowns. J Dent 2016;55:1-6

How to cite this article: Bakshi S, Gupta R, Komal, Verma S, Bhat IA. Recreation of esthetic smile smile from flared anterior teeth with midline diastema utilizing zirconia ceramic fixed bridge: A case report. Ann Prosthodont Restor Dent 2019;5(4):131-4. 